ISSN: 2277-3754

ISO 9001:2008 Certified

International Journal of Engineering and Innovative Technology (IJEIT)

Volume 10, Issue 5, November 2020

\title{
A Case Study of Optimum Energy efficient routing using SAA Approach for WSN
}

\author{
Priyanka Chourey, Imran Ali Khan \\ Bansal Institute of Research \& Technology, India
}

\begin{abstract}
The IOT based wireless sensors network (WSN) gas become an integral part of many smart applications for acquiring data over cloud/servers. Since life of networks are restricted by power availability of sensors. As sensor node acts as a switch in the network thus, assurance of efficient routing becomes the essential part to prolonging the utilization of energy. Therefore, it is mandatory to enhance the energy efficiency of these WSN systems. The sleep aware and awake method is widely used for saving the energy of the WSN networks. This paper proposes to design an efficient routing algorithm for WSN networks via examination and testing of numerous state of art routing protocols related to WSN. The optimum parametric selection approach is used for designing the energy efficient $O$-EESAA protocol. Different experiments were conducted to test the efficiency and current clustering dependent EESAA protocol of the proposed optimal design. Performance is compared based on the network life time, alive nodes, latency as FND, and the number of packets transmitted. Overall proposed energy model is good enough to improve the energy uses of WSN.
\end{abstract}

Keywords: - Energy, Efficiency, Wireless sensor network, Clustering, Routing protocols, EESAA, network lifetime.

\section{INTRODUCTION}

Many researchers have opted WSN as a solution for smart data monitoring. Invention of the technology called Internet of Thing (IOT) the implementation of WSN become easier and scalability increased due to huge number of tiny nodes. The deploying WSN using the maximum energy efficiency (EE) is the major concern knowing the fact of limited storage and computation capacities of WSN [1] The huge coordination is required among the sensors nodes in order to produce desired spectral uses and results, It is highly required for WSN to utilize the minimum nodes energy for achieving maximum throughput efficiency. Basic concept adopted in paper is to improve the energy model of the network nodes. The major contributions of the paper are to enhance the network life and throughput and data uses by porting the optimum design parameters associated to improvement in network energy.

\section{A. IOT based Sensors Network}

IOT-WSN [3] consists of sensors for data acquisition and to communicate data from the field to WSN over cloud server as shown in the Figure 1.

Manuscript received: 25 October 2020

Manuscript received in revised form: 18 November 2020

Manuscript accepted: 08 December 2020

Manuscript Available online: 15 December 2020
For structure of the WSN network it can be observed from the Figure 1 that communication between the cloud serer and sensor unit is wireless. This consumes the most of the energy of WSN and is major challenge. It can be observed that each sensor has an independent battery associate to it and this s the only source of the energy of the nodes. An integrated IOT based sensor data logger must have a microcontroller and a ADC module used for reading the analog value and converting it to the digital form to store over the cloud. A Wi-Fi router is required to send the data wirelessly to the cloud server.

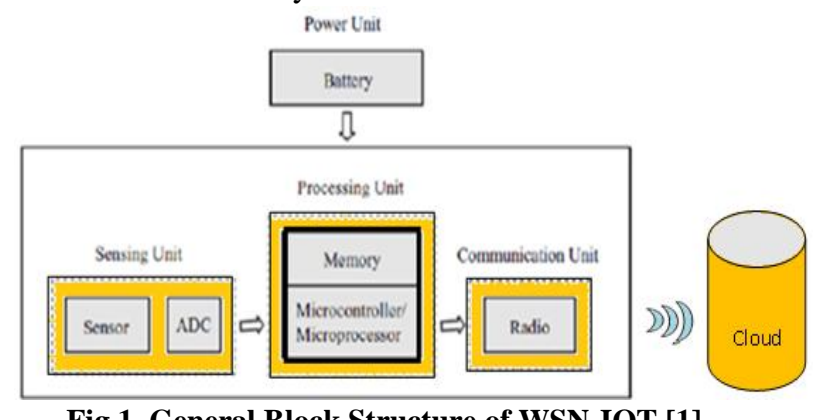

Fig.1. General Block Structure of WSN-IOT [1]

The maximum energy of WSN is consumed during communication. Usually the ADC is an inbuilt 10 bit resolution. The memory used is a flash memory reprogrammable. Paper validated the results of live nodes for the existing EESAA protocol by Ansam Ennaciri [2] and basic energy adaptive LEACH [5] protocols evaluated for comparing the performance. Then finally designs an optimum parametric selection based OEESAA protocol. Performance is measured in terms of latency defined as first node died count, network lifetime and the counts of the cluster heads $(\mathrm{CHs})$ to study the routing protocols.

\section{B. WSN Applications}

In recent times WSN becomes a most standard administrations or business option utilized in industrial monitoring and modern automation applications. The significant improvement in the processor technology made it easy to deploy the WSN in account of low-power use of sensing registering gadgets. The WSN consists of sensor as hubs called the cluster heads ( $\mathrm{CHs}$ ) that are used for sending the data of the environmental parameters monitored or sensed by nearby nodes too. These $\mathrm{CH}$ (hubs) can be utilized in different continuous long term WSN applications. For various transcendent tasks, such as shrewd detection, neighbour's hub disclosure, information processing and capability, information range, target monitoring, screen and control, synchronisation, 
ISSN: 2277-3754

\section{ISO 9001:2008 Certified \\ International Journal of Engineering and Innovative Technology (IJEIT) \\ Volume 10, Issue 5, November 2020}

containment and viable path between the base station and the base stations and hubs or nodes or $\mathrm{CH}$.

This WSN deployment can be implemented for the Web turning into a physical sensor network [6]. Applications are shown in the Figure 2. Sensor technology is exciting with interminable potential for some application regions like transportation, clinical, military, amusement, ecological, country emergency guard, the board and furthermore savvy spaces. Huge applications of WSN are the motivation behind the current research.

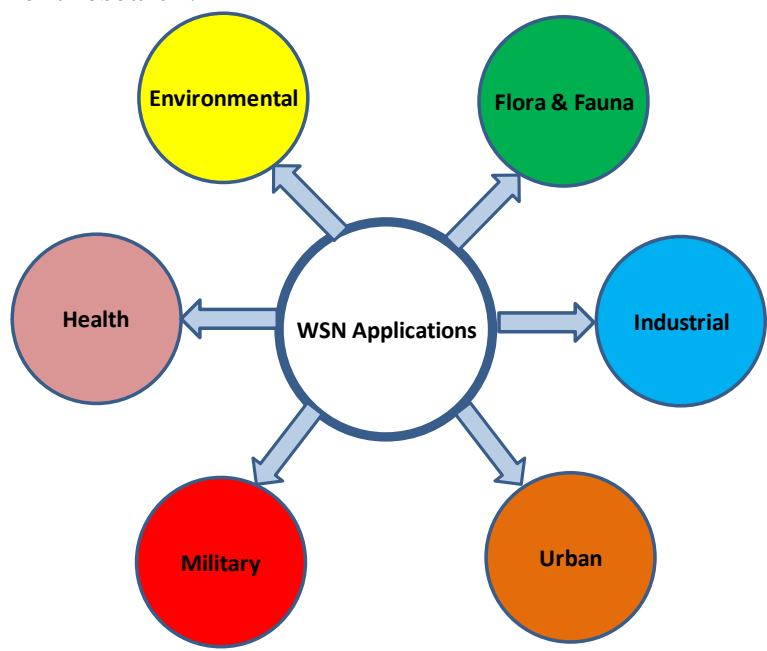

Fig.2.Application of WSN

\section{Energy Efficient Routing Protocols}

The use of the force assets and the drag of the network's life cycle when transferring information includes energy-producing routing protocols. Network focused on a remote sensor. WSN is a small, autonomous, call network of devices. Unmistakable physical monitoring forms can be accumulated by Sensors [4, 6]. Energy-efficient routing protocols for a wireless sensor network are an important concern (WSN). Sensors are known as the remarkable components of electronic equipment and embedded systems. For various applications of the WSN, essential and simple information has to be transmitted to the sink in a multifunctional way. Drawing the lifetime organization of WSNs as a basic problem, since the energy of the sensor nodes is limited. Specialists should consider the usage of energy at WSNs' routing conventions in order to broaden their lifespan. An additional extension of the EESAA [2] protocol was proposed in this text. In these days networks are growing so that the information collected is growing much bigger, all of which consume a lot of resources and kill a node early. Many energy-efficient protocols are therefore built to decrease the power used in the sampling and collection of data in order to prolong network life.Some energy efficient routing protocols are given below:

1. In this sort of hierarchy, most nodes communicate to the cluster heads. LEACH is the 'Low-Energy Adaptive Clustering Hierarchy' $(\mathrm{CH})$. The two stages are: (i). Step I of configuration: where the clusters were formed and organized, and $\mathrm{CH}$ was chosen. CH's job is to settle BS [7]. This process is longer than the preceding phase. The length of this stage has been extended to minimize the overhead. Every node in the network, touch and pass data to the cluster head and then $\mathrm{CH}$ is creating a schedule for the transmission of each node data to the basic station.

1. SEP [9]: Stable Election protocol: it is an energy efficient clustering based routing protocol cluster based on the stable election probability of the nodes. Total nodes are divided in to Norma, advance and intermediate nodes. SEP performs better then the basic LEACH protocols.

2. DEEC [7]: Distributed energy efficient based clustering based routing protocol. This is a three tire based energy efficient routing based on balanced threshold sampling.

3. EESAA [2]: The protocols based on energy efficient and sleep aware and awake based approach for improving the energy efficiency.

\section{LITERATURE REVIEW}

There has lot of work done for increasing energy efficiency of the heterogeneous networks. Usually this paper focused on the optimizing the design parameter based on investigation of the clustering based protocols using Sleep Aware and Awake approach. The primarily paper reviewed the work done for WSN protocol designing of energy efficient clustering based protocols. Komalpreet Kaur et al [1] have designed the enhanced protocol performance of the distributed energy efficient based routing using clustering (EDEEC). They have introduced additional supper node structure for improving the protocol lifetime and energy performance. Ansam Ennaciri et al [2] have designed the efficient energy balancing method using the sleep aware and awake (EESAA) methods. Priya et al [3] have designed the enhanced DEEC protocol using the clustering and distributed energy network. Initially they have used two tire normal and advance nodes for energy distribution therefore improves the performance in terms of lifetime.

Akshay Verma et al [4] proposed the fuzzy logic based routing method using effective clustering called as (FLEC) for homogeneous wireless sensor networks has been introduced for Mobile Sink. A fuzzy based protocol is used to extend the network life time. Khurana et al [5] have proposed new cluster head selection based LEACHMAC algorithm designed for the WSN Phanish, D et al. [6] have designed a routing protocol for designing an wireless sensor network for the application of football stadium structure health monitoring.

Kassim MR et al. [8] have explained various applications of the WSN in the monitoring of the health of the environment. Various sensors used for the environmental monitoring are described. Proposed novel 
ISSN: 2277-3754

\section{ISO 9001:2008 Certified \\ International Journal of Engineering and Innovative Technology (IJEIT) \\ Volume 10, Issue 5, November 2020}

method for cluster head selection for LEACH-MAAC protocol. Method was specific for MAC protocol.

Sercan Vançin et al [12] have designed a novel three tire based energy efficient routing protocol based on concept of the energy balanced threshold and sampling of the DEEC protocol. The summary of literature review is given in the Table 1. The current paper is focused to improve energy performance of the EESAA protocol.

Table 1. Summary of Review of routing protocols

\begin{tabular}{|c|l|l|}
\hline Authors & Methodology an energy & Approach \\
\hline $\begin{array}{c}\text { Ansam } \\
{[2]}\end{array}$ & $\begin{array}{l}\text { Designed multi layer } \\
\text { balancing approach } \\
\text { for EESAA protocol } \\
\text { balancing method for } \\
\text { performance } \\
\text { improvement in } \\
\text { energy of EESAA }\end{array}$ \\
\hline $\begin{array}{c}\text { Priya } \\
\text { et al [3] }\end{array}$ & $\begin{array}{l}\text { The improved the } \\
\text { energy performance of } \\
\text { the DEEC }\end{array}$ & $\begin{array}{l}\text { They have used an } \\
\text { extra supper nodes as } \\
\text { the third node tire }\end{array}$ \\
\hline $\begin{array}{c}\text { Mansi } \\
\text { Panwar et } \\
\text { al [7] }\end{array}$ & $\begin{array}{l}\text { Improved EDEEC } \\
\text { protocol designing }\end{array}$ & $\begin{array}{l}\text { Periodic threshold } \\
\text { based transmission of } \\
\text { WSN data. }\end{array}$ \\
\hline $\begin{array}{c}\text { Sercan } \\
\text { Vançin et } \\
\text { al [12] }\end{array}$ & $\begin{array}{l}\text { Design a three tire an } \\
\text { energy based efficient } \\
\text { routing }\end{array}$ & $\begin{array}{l}\text { balanced method of } \\
\text { threshold sampling }\end{array}$ \\
\hline $\begin{array}{c}\text { Proposed } \\
\text { Optimum parameters } \\
\text { design for extended } \\
\text { lifetime of EDEEC }\end{array}$ & $\begin{array}{l}\text { Improving energy } \\
\text { distribution for } \\
\text { extending latency }\end{array}$ \\
\hline
\end{tabular}

\section{EESSA PROTOCOL THEORY AND VALIDATION}

Without the efficient algorithm, the sensors will not be too efficient and will have shorter lifespan. Most research and development activities have been targeted at interpreting how to regulate energy consuming sensors in the network. In light of the issue of sleep and work-rest parameters among employees, the Energy Efficient Sleep Aware (EESAA) protocol proposed an algorithm that can manage the quality of employees' rest, productivity, and rest times. The authors implemented their EESAA algorithm on the computer-based MATLAB to prove the efficiency of the algorithm for load balancing where they compared the performance of our algorithm versus other available clustering algorithms.

\section{OPTIMUM EESAA PROTOCOL EDEEC}

Therefore in order to increase the network lifetime in this paper an extended protocol is designed called as EEDEEC. The network simulation parameters are optimally varied for improving the energy distribution of the network. It is observed that carefully choosing the coefficients of the advanced and supper node can improve the system performance. A modified supper node percentage factor is decided and constant $c_{g}$ is set to 0.2 for network distribution. The equation 4 is changed to

$$
\text { super }=n * c_{g}
$$

The advance node distribution ${ }^{m}$ is set to 0.3 , and the supper node coefficient for energy enhancement is set to $b=5$. It is observed the proposed modifications made significant improvement in the performance of protocol.
Values of the optimum initial transmitted and received energy and probability of elections of node and node distribution coefficients for the O-EESAA protocol is given in the Table 2 below.

Table 2. Node distribution and design parameters for EESAA protocol

\begin{tabular}{|c|l|l|}
\hline Variable & Notation & Value \\
\hline $\mathrm{N}$ & Number of the nodes & 100 \\
\hline$P$ & $\begin{array}{l}\text { Initial probability of } \\
\text { cluster heads }\end{array}$ & 0.2 \\
\hline Eo & Initial energy in J & $0.8 \mathrm{~J}$ \\
\hline$E_{F x}=E_{E x}$ & $\begin{array}{l}\text { Transmitted and received } \\
\text { energy }\end{array}$ & $50 \mu \mathrm{J}$ \\
\hline$E_{f g}$ & Free space energy & $10 \mathrm{pJ}$ \\
\hline$E_{D A}$ & Data aggregation energy & $5 \mu \mathrm{J}$ \\
\hline $\mathrm{A}$ & $\begin{array}{l}\text { Energy enhancement } \\
\text { friction }\end{array}$ & 3 \\
\hline$r_{\mathrm{max}}$ & $\begin{array}{l}\text { Maximum number of } \\
\text { rounds }\end{array}$ & 2500 to 5000 \\
\hline$m_{0}$ & Advance nodes friction & 0.4 \\
\hline $\mathrm{M}$ & Normal nodes friction & 0.5 \\
\hline
\end{tabular}

\section{VALIDATION OF PROTOCOLS}

In the Figure 3 the validation of protocols for the alive nodes performance of LEACH and EESAA protocols are presented. It can be seen that EESAA works better but life is short.

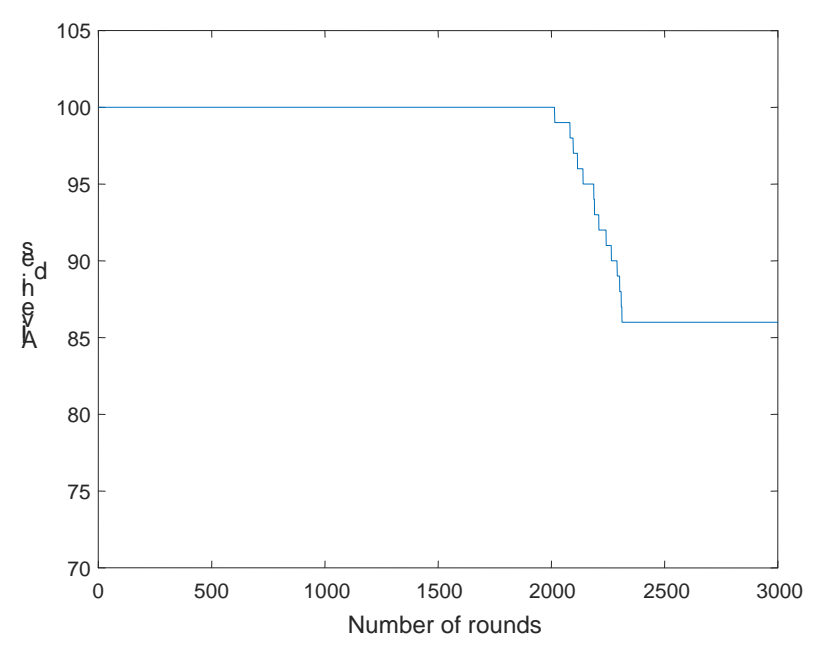

Fig.3. Validation of EESAA protocol alive nodes

\section{RESULTS OF O-EESAA}

This article compares performance with optimal parametric design of the energy-efficient O-EESAA protocol. In the works were the results of computer simulations with EESAA and Leach as comparison models. Our simulation protocol will be feasible because it was employed on the core dual-core chip running in MATLAB software. In this way, we can compare the performance of the O-ESAA and the EESAA protocols. O-EESAA performance is computed by comparing all the alive and dead nodes in Figure 6. It is evident that the OEESAA works better than the existing EESAA process. 
ISSN: 2277-3754

ISO 9001:2008 Certified

International Journal of Engineering and Innovative Technology (IJEIT)

Volume 10, Issue 5, November 2020

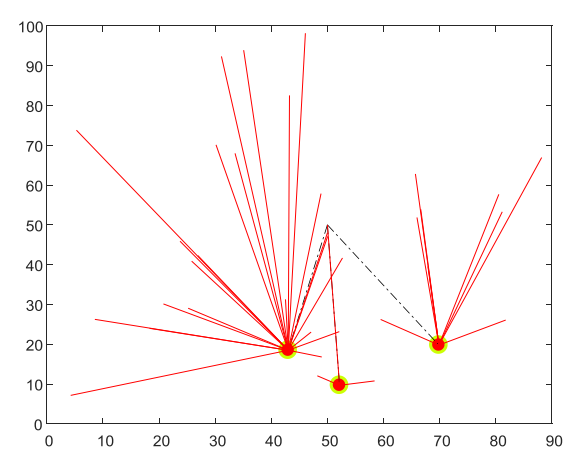

Fig.4.The node structure and cluster in EESAA protocols. Experiment 1: Performance evaluation of O-EESAA

This experiment is performed to evaluate and compare the performance of various routing protocols with a case of the optimum parameter SAA based protocol is shown in Figure 5.

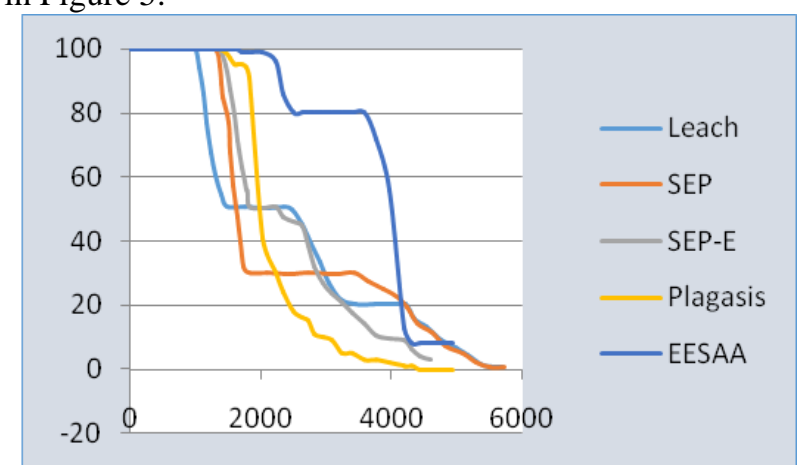

Fig.5.Evaluation of the various existing routing protocol with Optimum-EESAA protocol

Experiment 2: Number of FND for proposed protocol

In this section the number of the first node died (FND) is compared for the various existing routing protocols and the proposed routing protocol with optimum parameters. It can be observed from Figure 6. Comparison of packets transmitted to BS for various routing protocols with proposed O-EESAA protocol is given in Figure 7. Improvement in performance by proposed O-EESAA can be observed from all results.

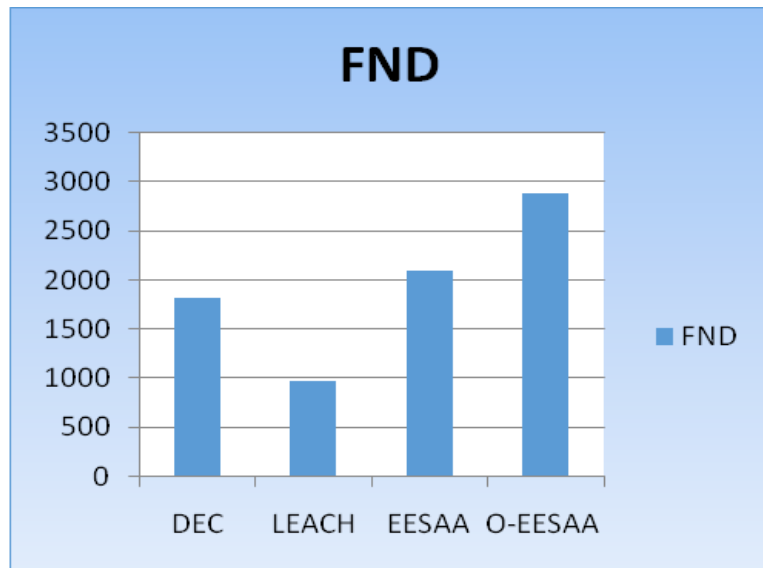

Fig.6.Comparison of number of FND for various routing protocols with proposed O-EESAA protocol.

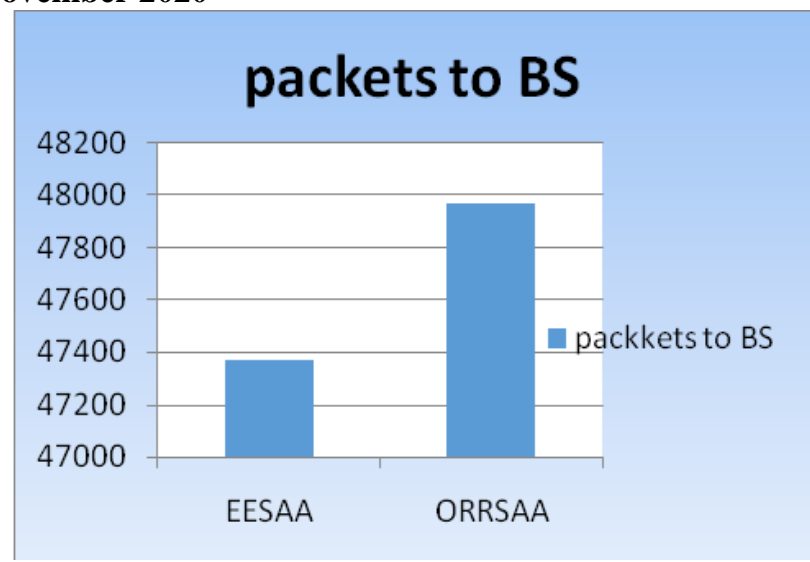

Fig.7. Comparison of packets transmitted to BS for various routing protocols with proposed O-EESAA protocol.

VII.CONCLUSION AND FUTURE SCOPE

The WSN is essential for the area of IOT and requirement of energy efficient routing is always a challenging task. Paper proposed to design the improved performance of the EESAA protocol. The goal was to design the energy efficient routing protocol and performance comparison with the state of art LEACH, SEP, DEC, and EESAA protocols. The proposed OEESAA protocol transmits 400 more packets to BS compared to EESAA protocol. Similarly the lifetime in terms of the FND is improved by around $31 \%$ by using the O-EESAA protocol compared to EESAA.

This emphasize that O-EESAA protocol is more energy efficient compared to all other protocols mentioned here. Over all paper contributes significant improvement in energy performance and lifetime of the WSN.

\section{REFERENCES}

[1] Komalpreet Kaur, Shivani Sharma, "Enhanced Distributed Energy Efficient Clustering Protocol”, International Conference on Computer Communication and Informatics (ICCCI -2020), Coimbatore, INDIA 22 - 24, Jan 2020.

[2] Ansam Ennaciri, Mohammed Erritali, Jamaa Bengourram "Load Balancing Protocol (EESAA) to improve Quality of Service in Wireless sensor network", Elsevier International Workshop on Web Search and Data Mining (WSDM) April 29-May 2, pp: 1140-1145, 2019.

[3] Priya"EDEEC-Enhanced Distributed Energy Efficient Clustering Protocol for Heterogeneous Wireless Sensor Network (WSN) Scheme for WSN", International Research Journal of Engineering and Technology, Volume: 04 Issue: 08, pp: 1107-1110, Aug -2017.

[4] Akshay Verma , Sunil Kumar, Prateek Raj Gautam , Tarique Rashid, and Arvind Kumar, "Fuzzy Logic Based Effective Clustering of Homogeneous Wireless Sensor Networks for Mobile Sink", IEEE Sensors Journal, Vol. 20, No. 10, pp:5615-5623, May 15, 2020.

[5] Khurana, B., P., \& Kant, K., "LEACH-MAC: A new cluster head selection algorithm for wireless sensor networks", Journal of Wireless Networks, 22, pp: 49-60, 2015.

[6] Phanish, D. Garver, P. Matalkah, G. Landes, T. Shen, F. Dumond, J. Abler, R. Zhu, D. Dong, X. Wang, Y, "A 
ISSN: 2277-3754

\section{ISO 9001:2008 Certified \\ International Journal of Engineering and Innovative Technology (IJEIT) \\ Volume 10, Issue 5, November 2020}

wireless sensor network for monitoring the structural health of a football stadium", In Proceedings of the 2015 IEEE 2nd World Forum Internet Things (WF IoT), Milan, Italy, pp. 471-477, 14-16 December 2015;.

[7] Mansi Panwar, S.D. Samantaray, "An Improved E-DEEC Protocol using Periodic and Threshold-Sensitive Data Transmission in Heterogeneous Wireless Sensor Network", International Journal of Computer Science Engineering (IJCSE), Vol 4,Issue 4,pp:155-161,2015.

[8] Kassim MR, M., Harun, A.N,"Applications of WSN in agricultural environment monitoring systems", In Proceedings of International Conference on Information and Communication Technology Convergence (ICTC), Jeju, Korea, pp:344-349, 19-21 October 2016.

[9] Georgios Smaragdakis Ibrahim Matta Azer Bestavros, "SEP: A Stable Election Protocol for clustered heterogeneous wireless sensor networks", Second International Workshop on Sensor and Actor Network Protocols and Applications, pp: 1-12, (SANPA Nov 2004).

[10] Dionisis Kandris, Christos Nakas, Dimitrios Vomvas and Grigorios Koulouras, "Applications of Wireless Sensor Networks: An Up-to-Date Survey", MDPI journal of applied system information, pp: 1-24, Vol. 3, Issue 14, 2020 .

[11] Amee Vishwakarma,Papiya Dutta, "Comparative Analysis of DEEC protocol with Various Energy Efficient Clustering Protocols of WSN's"' in Journal of Emerging Technologies and Innovative Research (JETIR),pp:235248, Volume 4, Issue 082017.

[12] Sercan Vançin and Ebubekir Erdem, “Threshold Balanced Sampled DEEC Model for Heterogeneous Wireless Sensor Networks", Wireless Communications and Mobile Computing. Hindawi, pp: 1-12, Volume 2018.

[13] Zantalis, F., Koulouras, G., Karabetsos, S., Kandris, D,"A review of machine learning and IoT in smart transportation", Future Internet Vol. 11, Issue 94, pp: 1-23, 2019.

[14] Ch. Usha Kumari and Tatiparti Padma, "Efficient data gathering algorithm in wireless sensor networks with optimal path mobile sink". Journal of Wireless Communications and Mobile Computing, pp:1-8, 2015.

[15] Sahraei, S. H., Kashani, M. M. R., Rezazadeh, J., \& Farah Bakhsh, R., "Efficient job scheduling in cloud computing based on genetic algorithm", International Journal of Communication Networks and Distributed Systems, pp: 447-467, Jan 2019.

[16] Tyagi S, Kumar N., "A systematic review on clustering and routing techniques. Based upon LEACH protocol for wireless sensor networks", Journal of Network and Computer Applications, Elsevier, Vol. 36, issue 2, pp 623645, 2013.

[17] Kumar, V., Jain, S., Tiwari, S.,"Energy efficient clustering algorithms in wireless sensor networks: A survey". IJCSI international Journal of Computer Science Issues, 8(5), 2, pp: 259-268, Sep, 2011.

[18] Sharma, A. K., \& Kourtney, H., "Hybrid energy efficient distributed protocol for heterogeneous wireless sensor network", International Journal of Computer Applications, 4(6), pp: 1-5. 2010. 